\title{
Hosting as shelter during displacement: considerations for research and practice
}

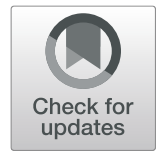

\author{
Cynthia M. Carone
}

\begin{abstract}
Hosting or local families taking in displaced families is an important way to shelter persons displaced during war or by natural disaster. While field-level evidence of hosting is on the rise, academic and policy-related scholarship on hosting is scant. Based on an extensive literature review and supplemented by the author's own work experience in the humanitarian sector, this paper identifies and summarizes ten aspects that shape the hosting environment and its associated support programs. These aspects provide insight to humanitarian actors that support hosting situations rather than allowing them to play out on their own. These aspects potentially serve (1) as programmatic criteria that humanitarian actors and aid agencies should consider when designing and supporting hosting programs and (2) are substantively rich areas that would expand the research agenda on displacement and humanitarian response and assistance. This paper has implications for both humanitarian practice and research, including how members of the humanitarian community conceptual hosting as a social relationship.
\end{abstract}

Keywords: Displacement, Hosting, Humanitarian assistance, Programming, Refugees, Research agenda, Social relations

\section{Introduction}

Scholarship on displacement that examines and problematizes the role of the camp in sheltering and protecting displaced populations goes back decades. However, there are other forms of sheltering the displaced following a conflict or a natural disaster that remain understudied. Hosting, local families taking in one or more displaced families, is one such understudied response. This paper examines hosting as a means for sheltering the displaced and identifies ten key aspects that make hosting a successful or challenging experience. These aspects form an initial list of concerns that practitioners and researchers should pay attention to and, which over time, could become a coherent set of variables that inform humanitarian practice. The paper specifically focuses on formal or intentional hosting programs; hosting programs where a humanitarian actor intentionally pairs up displaced families with local, host families, and/or supports already-existing spontaneous hosting situations rather than allowing them to continue without support.

This paper follows a well-established, intellectual tradition in development practice that relies on learning

Correspondence: CCaron@clarku.edu

International Development, Community and Environment (IDCE), Clark University, 950 Main Street, Worcester, MA 01610, USA from observation, from practitioner reflection on development activities done in the past (Schön 1994), and the existing literature to create what Hirschman called "insights of practical value" (Özçelik 2014, p. 1115). To that end, I draw on a number of sources: an extensive review of leading academic journals and the gray literature as well as my own work experience with international humanitarian organizations. The paper originates in a previous assignment to design a host family project in conflict-affected areas of Sri Lanka and my inability to find a substantial body of work that either indicated what made hosting programs successful or documented how families living in hosting environments made hosting work. This paper is a call for members of the humanitarian community to take stock of what is known about hosting as presented in the literature, to become more systematic in their thinking about hosting, and to recognize the complexities of the hosting environment in order to improve the sustainability of hosting relationships.

The objectives of this paper are three-fold: (1) to summarize aspects of the hosting environment, (2) to describe the financial mechanisms that support hosting, and (3) to orient scholars and practitioners to hosting as a rich and vital area for both research and practice. The discussion focuses on the operationalization of formal, 
host family programming emphasizing aspects of the hosting experience that members of host families, guest or displaced families, or potential host families ${ }^{1}$ identified as germane to making hosting successful or challenging. Illustrative quotes from persons hosting others or being hosted provide donors, governments, and humanitarian agencies with insights to improve hosting's success and sustainability.

I start with a brief history of hosting in sheltering the displaced followed by a presentation of the ten aspects identified in the review that characterize the hosting relationship. The aspects illuminate the complexity of hosting, identify knowledge gaps in humanitarian actors' understandings of how hosting works, and represent my initial attempt to create domains that humanitarian actors and evaluators might use to operationalize, conceptualize, and further analyze hosting in the context of displacement. Second, I describe the three dominant financial mechanisms that support hosting. Third, I suggest three programmatic additions and an associated research agenda to advance the humanitarian community's understanding of hosting in sheltering displaced populations. This paper has implications for both humanitarian practice, research, and evaluation. One practice implication is that members of the humanitarian community would approach hosting in a more systematic way, as they improve upon the ten aspects presented here and experiment more with financial package that support hosting. Improvement of hosting programs cannot take place, however, without evaluative research. Thus, one research implication of this paper is that donors invest not only in evaluations of the hosting programs that they support but also in information dissemination to share lessons learned. In doing so, the literature on hosting would increase and diversify, as evaluators and scholars of conflicts-affected societies incorporate hosting into their research agendas.

\section{Data and method}

In this paper, I use secondary data, particularly a review of the academic scholarship and the gray literature on displacement and refugee studies using university search engines. Documents contained in the review of the gray literature include project documents I wrote alone or with colleagues as well as project reports, evaluations, and communications materials found primarily online and published by donors and humanitarian agencies for the period 2005-2018. This period starts with the post-Indian Ocean tsunami period that coincides with my work in the humanitarian sector to the present. To find documents for review, I conducted a key word search using the following terms: host, hosting, host family, guest, guest family, host community, hospitality, and "shelter and displacement." As the main audience for this paper are practitioners and donors, I primarily rely on literature that provide insight into how formal hosting programs might be designed or evaluated and how already-existing hosting relationships might be supported. I reviewed the websites of international refugee agencies and humanitarian aid programs including but not limited to: the Danish and Norwegian Refugee Councils, CARE International, Helvetas, Swiss Development and Cooperation (SDC), the United Nations High Commissioner for Refugees (UNHCR), the United States Agency for International Development (USAID), the Sphere Project, the Shelter Project and International Federation of the Red Cross, and Red Crescent Societies (IFRC) searching for and reviewing communication materials, project documents, and evaluations that provide information about the hosting projects that they sponsor.

Observations from the literature review highlights the successes and challenges of humanitarian assistance programming with hosting the displaced in countries such as Sri Lanka, The Gambia, Haiti, the Democratic Republic of Congo (DRC), Lebanon, and Ethiopia. I enhance the literature review with quotes from interviews with persons living in hosting relationships that I conducted during Sri Lankan field visits and from meeting notes taken during aid agency meetings during my tenure at several international organizations in Sri Lanka from 2003 to 2009.

"We can't forget that when we needed help, they helped us. On their own expenses, our relatives have been looking after us for the past two months. We can't forget that." (Interview in Sri Lanka, December 2009)

\section{The role of hosting in sheltering the displaced}

While " $40 \%$ of all refugees live in camps" (UNHCR 2014, p. 2), refugees and internally displaced persons (IDPs) who do not cross recognized nation-state borders also find refuge outside of camps in rented accommodation, informal occupation of public or private land, or are taken in or hosted by friends, relatives, and often complete strangers. Hosting might occur spontaneously or be facilitated by aid agencies as part of humanitarian response. As the opening quote to this section illustrates, host families may provide food and shelter to displaced relatives or non-kin at their own expense.

While the public image of shelter in the context of large-scale displacement might be the camp, according to Nicholson, "ordinary people accommodating refugees in their homes is probably the oldest form of giving shelter to those who are displaced .... yet references to it have until quite recently been rare" (2013, p.1). Nicholson's archival research focuses on Albanians hosting persons fleeing advancing Greek troops during World War I 
(2013). Moore $(2003,2004)$ investigates the organization of Jewish rescue networks in Nazi-Occupied Europe during World War II. Whereas Nicholson's piece notes how Albanians took in kin and non-kin, Moore's historiography examines how individuals working within Jewish rescue networks recruited non-Jewish families to host persecuted Jews $(2003,2004)$. Moore states that individuals placing Jewish guests with non-Jewish hosts would pay attention to "age, gender, and appearance" of guest family members when pairing families up (2003, p. 302).

In addition to such evidence from World War I and II, there is a robust refugee studies scholarship that focuses on relationships between host communities and the refugee/IDP populations that come to reside in them during their displacement. This scholarship though privileges the relationship between the two groups including how their relationship may change over time with protracted displacement (Duncan 2005; Porter et al. 2008; Brun 2003; Sridarran et al. 2018). Practitioner manuals on humanitarian assistance focus more on host community-level needs rather than on matters that pertain to the individual host family (IFRC 2012; Davies 2012). When manuals do address the host family level, they tend to do so in reference to implications for host community relations and with an emphasis on technical issues vis-a-vis shelter needs (e.g., temporary shelter) rather than on relationships within the host family.

A host might host and provide refuge to a displaced family in its private home for a number of reasons either cultural principles of hospitality, generosity (Brun 2010, p. 345; Nicholson 2013, p. 7; Caron 2017), worthiness of the guest (Chatty 2013, p. 83) ${ }^{2}$, or local customs or obligations to help those in need (Nicolson 2013, p. 9; Chatty 2013; Moore 2003, 2004). For example, a woman in the city of Goma hosting a displaced family stated, "I just said: 'Come with me, you can stay at my house' ... I came to Goma in the war of 1996 and I was displaced again in 2002 by the volcano. I guess that why I said this" (Jeene 2009, p. 18). A woman spontaneously hosting a family displaced by fighting in Sri Lanka who I interviewed indicated that her decision to host was based on her own uncertain future in that conflict-affected province when she said, "if the same situation happens to us? ... we should accept them."

Setchell notes that "hosting by family and friends, or even by strangers, is socially defined, self-selected, culturally appropriate and typically provided before humanitarian actors arrive" (2012, p.17), and quite often lasts long after humanitarian workers leave. In Haiti, for example, between 500,000 and 600,0000 persons or $30 \%$ of earthquake-displaced persons lived with a host family for up to 10 months after the earthquake had struck (IFRC 2010, p. 3). Ninety percent of persons fleeing 2009 fighting in northwest Pakistan found shelter in host families (IASC 2010; Setchell 2012, p. 18). Recent writing on the influx of refugees into urban areas following sudden onset emergencies notes the crucial role that hosting plays in the short term until longer-term housing solutions are found (Zetter and Deikun 2011).

Keeping this literature on hosting in mind and with donors and humanitarian actors recognizing the utility and accepting hosting as a form of sheltering the displaced, formalized or intentional hosting programs, as I call them here, were an important intervention in humanitarian response following the 2004 Indian Ocean tsunami, the 2010 Haiti earthquake, and conflict-related displacements in the Democratic Republic of the Congo (Project Umoja) and Syria. This review of formal hosting programs lists out aspects for humanitarian actors to consider when designing formal hosting programs as well as questions that evaluators and researchers might ask about the hosting environment not only to improve hosting as a sheltering intervention but also to theorize more about cultures of hosting and hospitality.

\section{Aspects of hosting: considerations for practice and research}

Here, I present the ten aspects of hosting that emerged during data analysis. These aspects are pragmatic and programming aspects of hosting, defined as, when a host family accommodates one or more displaced families in private accommodation (i.e., the housing structure itself and the surrounding compound or yard area including any outbuildings). The ten aspects serve as program design features, represent a starting point for humanitarian actors considering either supporting or implementing a hosting program, and act as potential variables for research and evaluation. These aspects are multi-dimensional, complex, and are not as straightforward as they might appear. These aspects are not discrete. They interact with one another. As practitioners and evaluators consider these aspects, they may become important variables to guide how humanitarian actors implement hosting programs and facilitate an understanding of how host and guest family members experience the hosting environment.

Evidence of these ten aspects in the literature is uneven. The unevenness of practitioner and donor attention to them is evident in the length of their respective descriptions below. These descriptions, however, include statements from persons who have lived in hosting environments, indicating that these aspects are relevant to people who have lived in hosting relationships and as such should be considered by actors when matching families or facilitating hosting relationships. That said, neither humanitarian actors nor members of the host and guest families themselves can have prior knowledge 
of how the living situation between two families will unfold.

In the context of large-scale displacement, humanitarian actors supporting hosting might identify would be or potential host families ${ }^{3}$ and place or match them with displaced families. Identification or enumeration exercises of displaced families is often difficult not only because displaced families may be dispersed across often densely populated urban areas but also because some displaced persons may not want to be found, as they fear being discovered by persons from the areas that they have fled. Humanitarian actors may incur transaction costs associated with conducting enumeration exercises to identify and later match displaced families with hosts. Costs are not only incurred to locate and collect information from displaced and host families or through the administration of an application process to host or be hosted but also in time spent reviewing family information or applications to try to make a "good match" between hosts and guests as well as investing in a system to address challenges to the process and disputes that might occur should a match fail (discussed below).

\section{Placement with relatives (kin) or strangers}

Humanitarian actors implementing a formal hosting program must consider whether or not displaced families will be hosted by friends, relatives, or strangers. Nicolson's (2013) archival analysis of hosting in southern Albania in 1918 documents host families taking in both kin and non-kin fleeing advancing Greek troops. Moore's research found that persons working in rescue work In Goma, the Democratic Republic of Congo (DRC), nearly $25 \%$ of host families hosted total strangers. In some cases, the guest and host families had different ethnic or linguistic backgrounds (Shelter Projects 2009, p. 9; Jeene 2009). In Pakistan, nearly $90 \%$ of families displaced by conflict in the northwest between 2009 and 2011 stayed with host families. Quite often, families were not known to each other (Setchell 2012, p. 18). More recently, northern Lebanese families host non-related Syrian refugee families (Mackreath 2014). On the other hand, a Sri Lankan study found that $100 \%$ of displaced families interviewed were hosted by friends or relatives of the same ethnic Tamil or Muslim background (Caron 2006) and a post-tsunami project intentionally paired 6000 displaced families with relatives (Swiss Solidary and Helvetas 2006). In the early stages of host and guest family identification, humanitarian actors should determine whether or not host and displaced families would be willing to live with strangers or non-kin.

\section{Length of stay}

Displacement is often protracted. Not knowing when a war will end or when newly constructed houses to replace those destroyed in a conflict or by a natural disaster will be completed means that displacement could last weeks, months, or years making it difficult to fix an "end date" for the hosting relationship. Guests and host might not start negotiating a length of stay at the start of a hosting relationship. In Pakistan, host families did not know how long their guests would stay (Setchell 2012). In Sri Lanka, host family members often said that their guest family "can leave from us whenever they like" or stated that the length of stay would last until "the situation returns to normalcy, [then] they will go home" (Interview, October 2006). A guest family member residing with one of the host families quoted above confirmed this sentiment when she stated, "we promised that once the clashes are over we would go home" (Interview, October 2006). A 2012 Danish Refugee Council shelter assessment among Syrian refugees in Northern Lebanon found that approximately half of the Lebanese host families had hosted a refugee family for over 1 year (2012a, p. 1) with no indication that hosting would end. The review of the academic scholarship and gray literature did not find any studies that correlate length of stay with success of a hosting relationship. However, as a woman being hosted by a relative in northern Sri Lanka stated, "If we have difficulties, even if we have in our mind, we won't show it outside. If we stay for a long time, then it is [going to be] a problem" (Interview, December 2009). Uncertainty regarding the length of a hosting relationship and that guests might overstay their welcome could create anxiety for both host and guest family members. If so, an agreed upon duration may improve the health of the hosting relationship. The IFRC (2012) guidelines recommend that length of stay should be agreed upon by (1) the host family, (2) the guest family, and (3) an authority of the host community and last for a duration of 1 to 3 years.

\section{The physical dimensions of the hosting environment}

The size and the location of the host family's space (house and/or garden) also determine if a host can accommodate another family. Depending on the size of the host family's property, a host family might accommodate displaced families in a number of ways: (1) allocating one entire room in the house (either for rent or free) to the guest family, (2) sharing the same house or room with the guest family, (3) allowing the guest family to build a shelter on the host family's property (UNOPS 2008, 2010; Kesmaecker-Wissing and Pagot 2015; Caron 2017), or allowing guests to occupy an outbuilding on its property (Mackreath 2014). Depending on the size and lay out of the host family's house, sleeping and living arrangements vary. In the case of crowded housing 
conditions, men and elders might sleep outside, while women sleep inside (UNOPS 2010).

\section{Paying for accommodation}

As noted above, displaced families might be hosted for free or pay for accommodation. Whether or not the guest family will stay free of charge or pay rent for their accommodation is programming factor that must take into consideration. A displaced or guest family might pay the host family for taking them in or the host or guest family might receive financial assistance to support the hosting relationship (discussed below). Applied research from Sri Lanka and reviews of the scholarship and gray literature finds that both exist. Assessments of IDPs living with host families in Sri Lanka's northern Jaffna District did not find any host families charging rent (UNOPS 2010); however, another assessment of hosting in the Mannar District found that a majority of guest families paid rent for either a single room in a host family's house or for a space in its garden to erect a small shelter (UNOPS 2008, p. 5). Rents ranged between Rs. 300 and Rs. 3000 per month ${ }^{4}$ for hosted accommodation (UNOPS 2008, p. 5). Unfortunately, these rapid assessments neither indicate whether or not host and guest family members are related nor the guests' length of stay. They also do not indicate what percentage of monthly income guests spend on rent, making it difficult to determine if hosts exploit their guest families or not. Researchers and humanitarian agencies administering formal hosting programs should ask questions about such financial transactions to understand how they influence the hosting relationship.

Whether or not the host, guest, or both families would receive financial assistance to support hosting is another programming activity. Under CARE's Project Umoja in Goma, staff persons brokered a contractual agreement between the host and guest families stipulating that the guest family could stay rent free for 18 months (Jeene 2009, p. 19). Swiss Development and Cooperation (SDC) required that Lebanese families who wished to receive support to host displaced Syrian families provide their Syrian guests with rent-free housing plus free access to electricity and water (Esterman 2014). I discuss assistance that host and guest families may receive to support hosting more extensively later in the paper.

\section{Family size}

The number of persons in the host family and a potential guest family is relevant when placing families together. The aggregate number of combined family members may have implications for the success of the hosting relationship. As the two families will share the same space and resources over a period of time, overcrowding may lead to conflicts threatening the longevity of the hosting relationship. The literature documents a range of hosting numbers either as total number of persons or total number of families hosted. The number of guest family members that a host family might accommodate is usually less than 10 though 1918 census data from southern Albania reports that 1 host family accommodated 25 members of one extended family (Nicolson 2013, p. 14). Reports from the Democratic Republic of Congo and Haiti indicate that between five and nine displaced family members may live with one host family (Jeene 2009; IFRC 2012; Kesmaecker-Wissing and Pagot 2015). Alternatively, a host family may accommodate more than one displaced family. In Sri Lanka's Cash for Host Families Project, for example, host families accommodated up to three tsunami-displaced families for up to 6 months ${ }^{5}$ (Swiss Solidarity and Helvetas Sri Lanka 2006). CARE International's Project Umoja also placed more than one displaced family with a Goma-based host family (Jeene 2009). As one Project Umoja participant explained,

They turned out to be 18 in all. One of my sons grumbled about sharing the little food with so many, but I told him to shut up.... That was nine months ago, and they are still here (Jeene 2009, p. 18).

\section{Presence and number of children}

Adults and children make up a family unit. While the total number of family members matters with respect to the size of the host family's accommodation, the presence of children, particularly small children, may complicate the hosting relationship. Small children often behave in ways that make living uneasy. Displaced families who lived with host families noted that families with children might have problems. One young man put it this way:

The people who have come here ... are staying with their relatives but families with young children [they] won't tolerate this for a long time. ... People won't say it, but people with children will have problems (UNOPS 2010, p. 27).

Another group of men staying with host families noted,

We can only stay one or two months with relatives, otherwise the children will fight. The host families have more money and our children get upset because they see other children eating or getting things that we can't provide them. They are too small to understand (UNOPS 2010, p. 28). 
In another interview, a woman living with a host family stated, "The children are small and they disturb the older children in our relative's family. We don't feel good when our children disturb others" (Interview, 18 December 2009).

In order to manage family size and their subsequent dynamics on the hosting relationship, Kesmaecker-Wissing and Pagot (2015) note that in the Eastern DRC displaced families often divide their families up, sending children to various host families. The practice of separating and sending children to different host families occurred in Northern Sri Lanka too (UNOPS 2010). How family size and the presence of children influence the hosting relationship is not well documented; yet, child-parent separation is a recognized stressor for displaced/refugee children often with significant psychological and developmental outcomes (Macksoud and Lawrence Aber 1996; Fazel et al. 2012). Given that persons hosting or being hosted report that the presence of children is a source of concern, humanitarian actors should pay attention to the number of family members and their ages when pairing families not only to guarantee that families can stay together but also to design hosting assistance packages that meet family needs (more below).

\section{The status of the host family}

If humanitarian actors formally match host and guest families, then they need to understand how the ethnic, religious, clan, caste, or class status of potential host families might spark competition between local host families for hosting opportunities, especially in light of the shortages and scarcities that exist in the political economy of war. ${ }^{6}$ In the case of prolonged conflicts characterized by protracted displacement, humanitarian actors also must consider whether or not they would select long-term displaced families waiting to return home themselves to serve as host families. An assessment of protracted IDPs in Sri Lanka recorded a significant number of long-term IDP families hosting more recently displaced families (CPA 2006). Humanitarian actors need a clear definition of "host family" eligibility. Given that tensions might already exists between host communities and a long-term displaced population, the participation of long-term displaced families in hosting programs could lead to additional tensions if local host community families feel excluded if long-term displaced families are allowed to host the displaced.

\section{Sharing space}

Welcoming another family into one's home for an extended stay means that the two families need to find a way to live together and share the physical space of the house and its surroundings (e.g., garden). An assessment with Syrian refugees in Northern Lebanon illustrates the fragile nature of the hosting relationship. In 2011, a sample of Syrian refugees interviewed in the Northern Lebanese Akkar District found approximately 90\% of displaced Syrians living with a Lebanese host family. A follow up assessment in 2012 found that many of these families had left that host family and had moved into separate rented accommodation either because of "the unsustainability of the hosting environment" (Danish Refugee Council 2012a, p. 1) or that complaints that the host family house was too small. Not only did a small house or too many persons occupying that shared living space create an unsustainable environment, but displaced persons also reported that host families repeatedly told them to leave "because they were a burden on the household" (Danish Refugee Council 2012a, p. 5). Potential host families interviewed in Sri Lanka perceived that hosting could cause conflict and revealed hesitation about sharing their home with a displaced family in comments such as, "they would be obligated under our rules and regulations" and "they should live under our control" (Author interview, October 2006). In spontaneous hosting relationships in The Gambia, men who lived with host families noted that "they constantly felt like guests and had to comply with the hosts wishes" (Hopkins 2011, p. 12). Comments such as these underscore the social relations of hosting and the potential discomfort that inviting another family to live in one's home for an extended period of time might create.

\section{Sharing resources}

Other than sharing the physical space of their homes, host families share other resources with their guests including food, fuel, and clothing. Supporting the subsistence needs of a guest family can present a drain on host families especially when neither family receives additional, external assistance. Guest families in Sri Lanka noted that their hosts generously shared vegetables and occasionally meat and fish with them. One Sri Lankan study of host-guest family pairs found that $61 \%$ of family pairs shared food in at least one direction (i.e., host to guest or vice versa). In $25 \%$ of those pairs, both families shared food with one another (UNOPS 2008, p. 5). In the political economy of war with its scarcities and inflation rates, food sharing can create conflict between the two families. One woman clarified this type of tension when she said, "Our relatives are not making much so when we ask to share milk powder, they grumble that we have too many children" (UNOPS 2010, p. 28). In addition to food, there are other resources that Sri Lankan host families explicitly mentioned that they shared with guests: "We are sharing the toilet and well, but there is no electricity... we have to use more kerosene now that there are more children studying. It is difficult" 
(Interview, December 2009). This quote illustrates not only the types of resources shared but also highlights the financial burden of hosting. In order to address rising fuel costs, families in Goma shared the same cooking fire to save fuel expenses (Jeene 2009). Finally, while under no obligation to do so, host families might offer their guests a small loan to purchase foodstuffs or medicines (UNOPS 2010).

\section{Sharing activities}

Studying, cooking meals, and domestic chores are among the activities that host and guest family members do together. Despite the fact that children might create strains between the host and guest family, older children in host families who have not had either education disrupted often help younger guest children with their studies (UNOPS 2010). The same UNOPS study found that $21 \%$ of host and IDP families cooked meals together (UNOPS 2008, p. 6). As one father who has taken in his daughter and her family said,

My daughter and wife are doing the cooking together. If my wife goes to the temple, my daughter cooks. If my daughter needs to go to register or anything like that, then my wife cooks. That is our arrangement (UNOPS 2010, p. 27).

In cases where the host and guest families reported cooking separately, differences in food tastes and caste considerations were the stated reasons. Guest family members also help with household chores such as laundry, childcare, or gardening; this was true even in a pilot project where host families were paid to take in tsunami-displaced families as their guests (SewaLanka Foundation 2005a).

The number of persons including children that need accommodation, whether or not the displaced and the host family know one another, and the size of the space available, are programmatic aspects that humanitarian actors can objectively verify. How displaced and host family members will live together on a day-to-day basis is less easy to know. Humanitarian actors and donors need research that takes the hosting relationship as the unit of analysis and focus on host and guest family dynamics as well as outcome evaluations that demonstrate what aspects influence the success or longevity of the hosting relationship.

This presentation of the ten aspects draws from the current literature and my own work experience in Sri Lanka. Each aspect's current characteristics might be redefined and problematized. These aspects serve as a starting point for humanitarian actors and evaluators to be more systematized in how they design and evaluate hosting. The literature review also identified financing mechanisms that support hosting relationships, which I discuss next.

\section{Current practices for financing hosting}

Unlike the ten aspects, reports published by donors and the humanitarian agencies that they support provides detailed descriptions about the financing of hosting programs, which is reflected in the descriptions below. Since the early 2000s, there have been three dominant humanitarian interventions that support families living in hosting relationships. Such interventions attempt to reduce the financial burdens of hosting (Swiss Solidary and Helvetas 2006; Davies 2012; Setchell 2012; Mackreath 2014). As Setchell notes, without some form of support, hosting relationships in Haiti would "have strained the patience and resources of all" parties concerned (2012, p. 18). Here, drawing from the literature review, I summarize features of the financing packages humanitarian actors have provided to families in hosting relationships. These are (1) cash assistance and/or in-kind assistance to host families only, (2) cash and/or in-kind assistance to displaced or guest families only, and (3) assistance to both the host and guest family. Based on the evidence available and to the extent possible, I focus on the goods and services delivered, to whom, and where possible the process of delivering assistance.

\section{Cash and/or in-kind assistance to host families}

Cash payments to host families offer a potential solution to the financial stress hosting poses. Direct cash transfers to host families are a popular intervention in both post disaster and conflict environments. Following the 2004 Indian Ocean tsunami, for example, Helvetas implemented a Cash for Host Families Project (CfHF) in Sri Lanka's eastern province. Helvetas staff members coordinated with local government officials to select approximately 6000 local host families each of whom received approximately 200 USD (roughly 33 dollars per month) to host a tsunami-displaced family (relatives or friends) in their house or compound for a period of six months. In some cases, host families sheltered more than one family at the same time for no extra compensation (Swiss Solidarity and Helvetas Sri Lanka 2006). The CfHF Project presents an opportunity to examine what short-term hosting could look like. Two third-party CfHF evaluations found that over $50 \%$ of the project's host families reported sharing a portion of the cash distribution with the guest family and spent the remainder on electricity and water bills, household goods, and food (SewaLanka Foundation 2005a, 2005b). With the money received from the host family, guests reported buying food and household supplies, contributing to electricity 
payments, and paying outstanding debt and children's school fees (SewaLanka Foundation 2005b). Only 4\% of host families reported that they saved the entire cash distribution received, neither sharing it with their guests nor spending it on immediate family needs (SewaLanka Foundation 2005b). In over two-thirds of cases, the host and the guest family jointly decided how to spend the cash payment (Swiss Solidarity and Helvetas Sri Lanka 2006, p. 15). More recently, a Swiss Development Corporation-funded hosting project with displaced Syrian families in Lebanon provided Lebanese host families USD 170 to accommodate up to nine displaced persons (Esterman 2014, p. 29). Lebanese host families also received USD 600 to complete two household improvement projects (Esterman 2014, p. 29). Much like the CfHF project in Sri Lanka, Lebanese families received cash transfers or reimbursement for work completed. In addition to cash transfers to host families, host families often receive materials to improve the living space. In CARE's Project Umoja, for example, host families received construction materials to extend their pre-existing homes, increasing the per unit living space by $2.25 \mathrm{~m}^{2}$ per person, reflecting a $50 \%$ increase in space per person (Jeene 2009, p. 11).

\section{Cash and in-kind assistance to displaced or guest families}

Some assistance programs specifically targeting guest families provide cash transfers to help cover some of the costs of their host family accommodation (NRC and IFRC 2013). Cash transfers to the guest family complement traditional cash-for-work programs that help IDPs or refugees pay rent or contribute to host family household expenses. The Danish Refugee Council, for example, provided cash assistance to Syrian refugee families to pay rent to their Lebanese host families (Danish Refugee Council 2012b). Project Umoja, on the other hand, required an 18-month, rent-free period for guest families and provided two separate vouchers to the displaced family for the purchase of food and non-food relief items (Jeene 2009, p. 9).

\section{Assistance to both host and guest family}

Assistance to both the host and the guest family is another programming option pursued in a number of contexts including Pakistan, Haiti, and the DRC. CARE International's host family project, "Project Umoja" in the DRC brought host families together with one or more guest families in pairings that they called solidarity families (Jeene 2009; Shelter Project 2009, p. 9). Each host and guest family received a hundred US dollar food voucher, which allowed families members to decide what food stuffs to buy and when (Jeene 2009). The USAID Office for Foreign Disaster Assistance (OFDA) reported spending nearly \$75 million in 2009 and 2010 "in combined assistance for Pakistan's conflict-affected individuals" (Setchell 2012, p. 18) to directly benefit IDP and host families. In Haiti, one program paid 1 year of school fees for displaced children living in host families while the host family received a one-time unconditional cash grant for hosting them and their family (IFRC 2012, p. 45). The IFRC promotes assistance to both host and guest families, suggesting a particular delivery system. The host and the guest family should be considered as one family unit, and therefore "as a single recipient unit: the solidarity family."7 The IFRC manual states that support be provided based on the needs of each solidarity family unit and that "displaced individuals and host families must agree on how support is divided between families before the support is actually provided and such agreements must be endorsed in writing by an appropriate local authority or committee" (2012, p. 13).

Discussions about financing hosting relationships in the literature proceed with little recognition of how the ten aspects above might matter to their success. Donors concerned about the impact of their investment might want to think more about, for example, how the age and number of children influences the distribution of financial assistance between and among guest and host family children as well as how family members decide how to spend funds received by donor agencies and how that decision making dialog influences the health of the hosting relationship.

Zetter and Deikum further argue that strategies that support host families without undermining local "hosting culture" are needed (2011, p. 48). Like the abovementioned discussion of hosting aspects, there is little scholarship that explores how financial support, which might be argued to commodify the hosting relationship, might influence already existing hosting culture, and with what consequences. Scholarship on hospitality in the refugee studies literature shows, for example, how Islamic values shape host-displaced community relations in Sri Lanka (Brun 2010) and explains why families hosted displaced families in Albania (Nicholson 2013). Such research provides insight into how practitioners might hold stereotypes about what motivates host families. Calls for programs to support host families made at a UNCHR protection meeting in Colombo in 2007, for example, were dismissed by an expatriate aid worker with claims that they "would spoil the culture of hospitality in Sri Lanka" and that host families "would only come forward to host in order to make a profit" (Meeting notes, UNHCR Protection Meeting, Colombo, Sri Lanka). No evidence was offered to support these claims. It is unclear if such statements are true. There is little understanding about how financial support intersect with local hospitality norms and if and how financial support would "corrupt" local hosting practice. Equally 
important is Nicholson's request for research on circumstances when displaced families are turned away by potential hosts and why (2013, p. 19). An initial understanding of local hosting culture could improve support programs by making them more context relevant. Finally, there are questions to ask of donors and humanitarian actors. For example, in which contexts (war or natural disaster) are donors more likely to support hosting programs over the establishment of camps or other shelter arrangements and for what reasons? Such questions are part of an emerging research agenda that constitutes the future of hosting.

\section{Future directions for hosting program design and implementation}

The aspects of hosting and current humanitarian interventions that support hosting programs highlight the factors that might create a successful hosting environment or endanger the hosting relationship. Considering the everyday interactions that take place within the hosting environment invites practitioners and researchers to think about how aspects such as family size, number of children, length of time, and kinship influence host and guest social interaction and how humanitarian interventions themselves might structure or influence a hosting relationship. Based on this review, I suggest three new substantive programmatic areas where humanitarian actors might direct their attention. Doing so not only complements the above discussion but also brings attention to the principle of protection that guides humanitarian action, providing an architecture for a research agenda to better understand hosting.

\section{Guiding principles and minimum standards for hosting}

In order to create a physical environment that is comfortable given the addition of guest family members, humanitarian actors should create a culturally and context relevant, and therefore, list of potential goods and services that address host and guest family needs. Such a list may include the goods and services the guest family needs and will receive, a minimum length of stay, as well as other factors, which may include but are not limited to sleeping arrangements, access to electricity and potable water supply, and the ability to use the kitchen and/ or toilet.

The costs that the host family is expected to bear on the guest family's behalf, an initial end date for hosting (with the possibility of renewal), the external benefits that the guest family has access to, and what the host family will receive must be clearly communicated to both families. Failure to communicate such information compromised the success of an Ethiopian Out of Camp (OCP) scheme. The Government of Ethiopia piloted an "out of camp" scheme in 2010. With the sponsorship of an Ethiopian relative who would serve as a local host, individuals were allowed to leave the camp to live and work (Samuel Hall Consulting 2014). A review of this scheme found that while a refugee could find a family sponsor who was willing to host him/her, the sponsoring relative was often unwilling to cover food and basic needs to support the transition from refugee camp to the city. In other cases, the sponsoring relative expected that the refugee would have access to financial assistance to help the host family (Samuel Hall Consulting 2014, p. 40). The fragility of many of these Ethiopian sponsorships led refugees to return to the camp or engage in risky coping mechanisms such as skipping meals or sex work (Samuel Hall Consulting 2014, p. 42).

Even though local context and cultures of hosting will influence the social dynamics of any hosting relationship, practitioners formalizing and supporting hosting should consider creating minimum standards informed by the ten aspects. Examples of initial standards could include keeping displaced families (parents and children) together and providing a hosting environment that seeks to minimize competition for space, privacy, and resources: areas that the review identified as sources of tension. The hosting environment needs to ensure privacy and security for both families to maintain physical and emotional health during the hosting period.

Standards must incorporate previous critiques of other shelter standards such as SPHERE (Tong 2004; Morris et al. 2007). Standards must be based on principles that appreciate the socio-cultural conditions and living conditions of host and guest families, and focus on issues beyond logistics, mechanics, and materials (San Juan 2003), and take note of the principles laid out in the Humanitarian Charter (SPHERE Association 2018). The next two substantive areas expand beyond the materiality of hosting, focusing on its social dimensions.

\section{Mitigating and anticipating disputes}

That hosting potentially creates strain and hardship for both the guest and host family is evident when displaced persons who live in camps say that they have not contacted nearby relatives "because we do not like to give them trouble" (Interview, October 2006). Sri Lankan interviews as well as case studies published in donor reports and related communication materials indicate that sharing food, space, and household goods can cause financial strain for host families resulting in disputes (Hopkins 2011; IFRC 2012; Argenal and Setchell 2014; Kesmaecker-Wissing and Pagot 2015).

Given that many host families struggle to fulfill their own basic needs in the political economy of war or disaster (UNOPS 2008; Hopkins 2011; Brookings Institution 2012; IFRC 2012), they too may need support. Giving aid or incentives to only one family in the hosting 
relationship increases the potential for conflict between the two families (Swiss Solidarity and Helvetas Sri Lanka 2006; IFRC 2012). Length of stay, host family income, the size and/or the number of children in the guest family, and the general nature of displaced-host community relations are among the variables that may increase the likelihood of disputes, especially if host families and communities receive no external support (Argenal and Setchell 2014).

Humanitarian interventions can create tensions as well. The evaluation of the Sri Lankan Cash for Host Family Project found that 5\% of host families reported that the cash payment increased tensions with the guest family, resulting in the guest family leaving as the payment had not been shared (SewaLanka Foundation 2005a, p. 6). Giving aid to both the host and guest family could avoid such instances, as could IFRC's recommendation that the host and guest family agree upon in writing the division of jointly received support. Relationships are not static. Disputes between the guest and the host family might emerge even if living arrangements are agreed-upon in writing beforehand and both families receive assistance. Humanitarian actors need to design hosting programs with an understanding of how and what types of disputes might emerge, take steps to mitigate them, and include a grievance mechanism should they arise.

\section{Support services and social integration}

To address the emotional and psychological well-being of families during hosting, humanitarian actors might provide counseling or similar services that would allow host and displaced families to discuss in private or as a group both the challenges that emerge from inhabiting a shared living space as well as problem solving. Just as Feldman (2015) writes that camps are emotional spaces marked by uncertainty, the homes of host families are emotional spaces too, as both host and guest family members learn to live with one another and cope with the dynamics of the larger socio-political context within which they live.

Long-term dependency, inability to participate in host community life, and feelings of indebtedness may cause emotional harm for guests and increase tension with their hosts. A strength of one of the Haitian interventions discussed above was that paying the school fees for displaced children not only reduced a financial burden of parents but also improved the psychosocial health of children and helped them integrate into the host community (IFRC 2012). For adults, employment-related services or training programs serving both guest, host family, and host community members help to reduce financial dependency and isolation that guest family members may experience. The inclusion of host family and community members into such programs promotes interaction that may have implications for wider IDP-host community relations. Such support and social integration services may help humanitarian actors fulfill the obligation that displaced or guest families are able "to exercise their rights and freedoms" and make "meaningful choice regarding their lives" (UNHCR 2014, p. 12). While education, livelihood services, and training programs have material dimensions, the effects that they may have on social relations and well-being cannot be ignored and maybe necessary to make hosting a feasible, sustainable, and dignified way for displaced families to live.

\section{Hosting as a research agenda}

The literature on hosting does not include evidence of rigorous evaluations that try to explain what factors and what types of financial mechanisms contribute to a successful hosting relationship. Next, I present examples of four research domains with associated research questions. These research domains are illustrative and not exhaustive. They are an initial attempt to guide evaluators and researchers to the types of questions that intersect with the ten aspects above and would help donors and practitioners to understand the outcomes and lived experience of hosting.

\section{Motivations for hosting}

What reasons do hosts provide for taking in guests? With the existence of financial support programs and in light of the type of comment about profiteering raised at the protection meeting discussed above, documenting motivations and disaggregating them by variables such as class or household status (married vs widowed households) would provide practitioners with insights into the potential sustainability of a host-guest pairing. Research conducted by sociologists and historians of the Holocaust shows that the hosting of Jews in Nazi-Occupied Western Europe was not always for moral, religious, or altruistic reasons, but also for "less-heroic" reasons such as forced conversion to Christianity and material gain (2004, pp. 394-395). Moore argues that Holocaust Studies scholars still do not understand whether or not taking in a guest was the male/husband's decision or a collective decision between a husband and wife (2003, p. 302). Knowing how hosts arrive at the decision to host and the household-level power relations that inform that decision-making would help practitioners, as they approach potential families to host guests.

\section{Hospitality and the transactional nature of hosting}

Given evidence that hosting has both altruistic and less altruistic motivations, researchers and evaluators might ask the following types of questions about the hosting environment, "How do cultures of hospitality change 
under conditions of protracted displacement, when there is no end in sight?", "Does paying rent influence the length, duration or tone of the hosting relationship, and if so, to what extent?" and, lastly, "How might ethnic, religious, clan, caste, or class background spark competition among potential host families for hosting opportunities?" Answering questions about practices of hospitality is also an excellent example of how hosting research might bridge academic scholarship and applied research.

\section{Context of hosting}

Researchers and evaluators might examine, if and how, hosting relationships are different in conflict-affected environments or following a natural disaster, and if so, how do these relationships differ? They might investigate how and the extent to which hosting relationships differ in urban or non-urban environments as well as consider if refugees experience hosting differently from IDPs. Such comparative studies would help donors think more strategically about when and where they fund hosting programs.

\section{The social relations of hosting}

Questions with respect to the social relations of hosting might include, "Do pairings with friends, relatives or strangers matter to the success or longevity of a hosting relationship and if so, how?" as well as "How does the class status or income level of the host and guest families influence whether or not conflicts over resource sharing occur with the hosting relationship and, if so, how do conflicts manifest themselves?"

Asking questions about the hosting experience, learning about how hosting interventions work, and why they do or do not work well presents members of the humanitarian community with evidence that they could use to construct better design principles to guide formal hosting programs, including revising/informing the ten aspects presented above.

\section{Conclusion}

Families hosting displaced families as a result of conflict or a natural disaster is a long-standing practice currently garnering attention in the media and in the public communication materials and practitioner reports published by humanitarian agencies. This paper based on my work experience in Sri Lanka's humanitarian sector and a review of the recent academic scholarship and gray literature summarizes and outlines the aspects of hosting programming that humanitarian assistance workers should take into consideration when either facilitating a formal hosting program or supporting already existing relationships in order to enhance the sustainability of the hosting relationship.
Hosting is a logistical and social exercise. That humanitarian actors and their donors acknowledge these ten aspects is an initial and critical step for success. Logistically, host and guest families either would be intentionally matched up or if hosting occurs spontaneously, hosts and their guests need to be visible to agencies in order to be included in formal hosting program so that such relationships do not play out on their own. As a social exercise, hosting involves unpredictable social relationships between two families who are under stress from displacement and its associated losses are becoming familiar with a new home environment, and the poverty and hardships associated with the larger political economy of war or disaster. A mutually agreed upon length of stay, for example, may provide a security of tenure that would reduce anxiety for the guest family about being displaced again. Cash incentives either as direct payments to host families for accommodating displaced families or receiving rent from their guests could alter hosting's social dynamics in unknown ways. While scholars and practitioners continue to debate whether or not cash incentives erode traditional forms of hospitality, Adams (2007) in her review of post-tsunami cash argues that

projects demonstrated an appreciation of the reality of hosting ... it allowed ... displaced families a degree of normality and a 'normal' family environment.

Rather than undermining traditional support systems it could be argued that they represented solidarity with host families (2007, p. 81).

The CfHF project evaluators also noted that they did not find that "receiving payment for this service [hosting] clashed with cultural norms" (SewaLanka Foundation 2005b, p. 9).

In summarizing hosting's recent history, hosting interventions, and the social relationships of hosting, this paper provides a direction forward as it presents an initial set of variables (the ten aspects) that potentially influence the hosting environment and suggests expanding the research agenda on displacement and humanitarian assistance and programming. Given the promise and potential that research on hosting can provide to practitioners and social scientists, the framing of hosting presented here may be expanded upon or re-conceptualized with additional applied research and further critical analysis of hosting and its embedded assumptions. This paper is such a call. Doing so may improve the hosting environment, protect both displaced and host family members, and increase our understanding of resilience in the context of displacement. 


\section{Endnotes}

${ }^{1}$ Potential host families are local families in the communities that displaced persons flee to, but are not hosting a displaced family. Such families have the potential to host. I use "guest" or "displaced" interchangeably to refer to the family that is hosted. Host family always refers to the family taking in or hosting that "guest" or "displaced" family.

${ }^{2}$ Anthropologists that write about hosting tend to emphasize the social and cultural nuances of hospitality and theorize about hospitality and treatment of guests and strangers drawing on the work of anthropologists such as Clifford Geertz and Marcel Mauss and the philosopher, Jacques Derrida. Humanitarian actors must try to understand local cultural context and norms of hospitality of the areas where they work. Given space constraints and this article's focus on programmatic action, I do not discuss anthropological theories on hospitality here. I do return to the importance of conducting research on how norms of hospitality might change in contexts where there is social disruption and where hosting becomes more transactional through the provision of hosting packages.

${ }^{3}$ Criteria to select eligible host families, as with the selection of any group of participants, could be done in a variety of context sensitive ways and in collaboration with local government authorities. Swiss Solidarity and Helvetas (2006) and IFRC (2012) provide examples of context relevant selection criteria and a selection process.

${ }^{4}$ The research was conducted in 2007 . The average Sri Lankan rupee value that year was Rs. 111 to one USD.

${ }^{5}$ Host families were not paid extra to host more than one family.

${ }^{6}$ I wish to thank one of the manuscript reviewers for bring this concern to my attention.

${ }^{7}$ Due to space constraints, I analyze assumptions about the unitary nature of the solidarity family elsewhere.

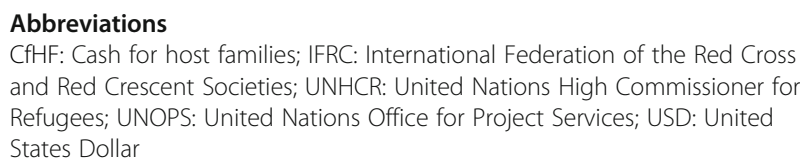

Abbreviations

CfHF: Cash for host families; IFRC: International Federation of the Red Cross and Red Crescent Societies; UNHCR: United Nations High Commissioner for Refugees; UNOPS: United Nations Office for Project Services; USD: United States Dollar

\begin{abstract}
Acknowledgements
The author thanks all the individuals in eastern Sri Lanka who spoke with her and her colleagues, providing their insights on a current hosting relationship or their own desire to host displaced families in the future. Alfred Jaeckle graciously shared his thoughts on hosting programs and provided key documents for this paper. Ken MacLean and Ramón Borges-Méndez, the journals' editors and two blind peer reviewers provided comments on earlier drafts, which significantly improve its clarity. The errors and oversights in this paper are the author's own.
\end{abstract}

\section{Funding}

The author received no funding to produce this paper.

\section{Availability of data and materials}

Data sharing is not applicable to this article, as no datasets were generated or analyzed during the current study. The journal articles and reports from the gray literature used for the literature maybe found on line. In several cases, links to the documents are provided to make supporting data available to readers.

\section{Authors' contributions}

The author conducted the entire literature review, analyzed the review's context, and wrote and edited the manuscript. The author read and approved the final manuscript.

\section{Competing interests}

The author declared that there is no competing interest.

\section{Publisher's Note}

Springer Nature remains neutral with regard to jurisdictional claims in published maps and institutional affiliations.

Received: 23 October 2018 Accepted: 30 January 2019

Published online: 01 March 2019

\section{References}

Adams $L$ (2007) Learning from cash responses to the tsunami: final report. Humanitarian policy group background paper. Overseas Development Institute, London.

Argenal E, Setchell C (2014) Supporting host families as shelter options' in Shelter Projects 2013-2014, pp 105-106 Available at: http://www.sheltercasestudies. org/shelterprojects2013-2014/Shelterprojects_2013-14_Lowres_WEB.pdf. Accessed 15 July 2016.

Brookings Institution (2012) 'Internally displaced persons and host communities: the limits of hospitality', (official transcript) Available at: http://www. brookings.edu/events/2012/03/22-idp-communities. Accessed 22 July 2016.

Brun C (2003) Local citizens or internally displaced persons dilemmas of long term displacement in Sri Lanka. J Refug Stud 16(4):376-397.

Caron C (2006) Hosting internally-displaced families: exploring the hosting experience in Batticaloa District. Arbeiter-Samariter-Bund, Colombo.

Caron C (2017) Hosting the displaced_and being hosted. Forced Migr Rev 55: $56-58$.

Cathrine Brun 2010 "Hospitality: becoming 'IDPs' and 'hosts' in protracted displacement". J Refug Stud 23(3): 337-355.

Center for Policy Alternatives (2006) A profile on internally displaced persons living with host families. Center for Policy Alternatives, Colombo.

Chatty D (2013) Guest and hosts: Arab hospitality underpins a human approach to asylum policy. Cairo Rev Global Affairs 9:76-85 Available at: https://www. thecairoreview.com/essays/guests-and-hosts/. Accessed 5 Jan 2019.

Consulting SH (2014) Living out of camp: alternatives to camp-based assistance for Eritrean refugees in Ethiopia. Samuel Hall Consulting, Addis Ababa Available at: http://samuelhall.org/wp-content/uploads/2014/05/Living-Outof-Camp-Alternative-to-Camp-based-Assistance-in-Ethiopia.pdf. Accessed 25 July 2018.

Danish Refugee Council (2012a) 'Accommodation of displaced Syrians in Northern Lebanon: Tripoli \& Akkar - June-July 2012', Available at: https:// data2.unhcr.org/fr/documents/download/36513. Accessed 20 July 2016.

Danish Refugee Council (2012b) 'Assistance for refugees and host families in Lebanon', Available at: http://reliefweb.int/report/lebanon/assistancerefugees-and-host-families-lebanon. Accessed: 19 July 2016.

Davies A (2012) IDPs in host families and host communities: assistance for hosting arrangements. UNHCR, Geneva Available at: http://www.refworld. org/docid/4fe8732c2.html. Accessed 13 July 2016.

Duncan CR (2005) Unwelcome guests: relations between internally displaced persons and their hosts in North Sulawesi, Indonesia. J Refug Stud 18(1): $25-46$.

Esterman J (2014) Towards a convergence of humanitarian and development assistance through cash transfers to host communities: a case study on Wadi Khaled and Akroum - Akkar District, Lebanon', CERAH Working Paper \#22. Geneva Centre for education and research in humanitarian action, Geneva Available at: http://www.cerahgeneve.ch/files/8514/6622/ 7068/WP22-convergance-humanitarian-development-assistance.pdf. Accessed 14 July 2016. 
Fazel M, Reed RV, Panter-Brick C, Stein A (2012) Mental health of displaced and refugee children resettled in high-income countries: risk and protective factors. Lancet 379:266-282.

Feldman I (2015) What is a camp? Legitimate refugee lives in spaces of longterm displacement. Geoforum 66:244-252.

Hopkins G (2011) Casamance refugees in The Gambia: self-settlement and the challenges of integration'. New Issues in Refugee Research, Research Paper No. 220. UNHCR Evaluation and Policy Analysis Unit, Geneva Available at: www.unhcr.org/4e79ef7c9.html. Accessed 14 July 2018.

Inter-Agency Standing Committee (IASC) (2010) Host families shelter response guidelines. Shelter cluster technical working group; Haiti shelter cluster.

International Federation of the Red Cross and Red Crescent Societies (IFRC) (2010) 'Coordinating shelter in Haiti: IFRC and the Shelter Cluster', Available at: https://www.sheltercluster.org/sites/default/files/docs/700300-haiti_ shelter_cluster-case_study-en-Ir.pdf. Accessed 19 Oct 2018.

International Federation of the Red Cross and Red Crescent Societies (IFRC) (2012) 'Assisting host families and communities after crisis and natural disaster: a step-by-step guide', Available at: http://www.ifrc.org/PageFiles/ 95186/IFRC\%20DRC\%20Assisting\%20host\%20family\%20guidelines-EN-LR.pdf. Accessed 27 July 2016.

Jeene H (2009) "Evaluation Project UMOJA: Care International, Goma, DR Congo". Ralsa Foundation. https://www.academia.edu/3194663/Evaluation_Project_ Umoja_cross_ethnic_solidarity_in_a_civil_war. Accessed 19 July 2016.

Kesmaecker-Wissing M, Pagot A (2015) Driven apart: how repeated displacement changes family dynamics in eastern DRC. The Internal Displacement Monitoring Centre, Geneva.

Mackreath H (2014) 'The role of host communities in North Lebanon', forced migration review \#47. Pp 19-21.

Macksoud MS, Lawrence Aber J (1996) The war experience and psychosocial development of children in Lebanon. Child Dev 67(1):70-88.

Moore B (2004) The rescue of Jews in Nazi-occupied Belgium, France and the Netherlands. Australian J Polit Hist 50(3):385-395.

Moore B (2003) The rescue of Jews from Nazi persecution: a Western European perspective. J Genocide Res 5(2):293-308.

Morris J, van Ommeren M, Belfer M, Saxena S, Saraceno M (2007) Children and the Sphere standard on mental and social aspects of health. Disasters 31(1):71.90.

Nicolson B (2013) Accommodating the internally-displaced in south-central Albania in 1918' Research Paper No. 267. New Issues in Refugee Research. UNHCR Evaluation and Policy Analysis Unit, Geneva Available at: http://www. unhcr.org/en-us/research/working/52ab272a9/accommodating-internallydisplaced-south-central-albania-1918-beryl-nicholson.html?query. Accessed 13 July 2016.

Norwegian Refugee Council and International Federation of the Red Cross (2013) 'Security of tenure in humanitarian shelter operations', Available at: https:// www.ifrc.org/Global/Documents/Secretariat/201406/ NRC\%20IFRC\%20Security\%20of\%20Tenure.pdf. Accessed 20 Mar 2016.

Özçelik E (2014) Albert O. Hirschman: a 'beamish' social scientist for our grandchildren. Dev Chang 45(5):1111-1133.

Porter G, Hampshire K, Kyei P, Adjaloo M, Rapoo G, Kilpatrick K (2008) Linkages between livelihood opportunities and refugee-host relations: learning from the experiences of Liberian camp-based refugees in Ghana. J Refug Stud 21(2):230-252.

San Juan R (2003) 'MSF positions vis-à-vis the SPHERE Project', Available at: https://www.msf.fr/sites/default/files/2003-03-25-VilaSanJuan.pdf. Accessed: 22 July 2018.

Schön DA (1994) Hirschman's elusive theory of social learning. In: Rodwin L, Schön DA (eds) Rethinking the development experience: essays Provked by the work of Albert O. Hirschman. The Brookings Institute, Washington, DC, pp 67-95.

Setchell CA (2012) 'Hosting support: an overlooked humanitarian shelter solution', January/February 2012, Monthly Developments, pp 17-18 https://www. humanitarianlibrary.org/sites/default/files/2014/02/hosting_support.pdf. Accessed 22 July 2018.

SewaLanka Foundation (2005a) Cash for host families Project: report on impact monitoring, Nintavur DS Division, Ampara District. SewaLanka Foundation, Colombo.

SewaLanka Foundation (2005b) Cash for host families project: report on impact monitoring in Sammanthurai, Kalmunai Muslim, Kalmunai Tamil, Karathivu and Sainthamaruthu DS Division, Ampara District. SewaLanka Foundation, Colombo.
Shelter Projects (2009) 'DRC, Goma - 2009 -conflict displaced case study: urban host families, vouchers Available at: http://www.sheltercasestudies.org/ shelterprojects2009.html. Accessed 10 July 2018.

Sphere Association (2018) The sphere handbook: humanitarian charter and minimum standards in humanitarian response, fourth edn, Geneva Available at: https://spherestandards.org/wp-content/uploads/Sphere-Handbook-2018EN.pdf. Accessed 8 Jan 2019.

Sridarran P, Keraminiyage K, Fernando N (2018) Acceptance to be the host of a resettlement Programme: a literature review. Procedia Eng 212:962-969.

Swiss Solidarity and Helvetas Sri Lanka (2006) Cash for host families project Sri Lanka. Final operational report. Helvetas, Ampara.

Tong J (2004) Questionable accountability: MSF and Sphere in 2003. Disasters 28(20):176-189.

UNHCR (2014) 'Policy on alternatives to camps', UNHCR/HCP/2014/9 Available at: http://www.unhcr.org/5422b8f09.pdf. Accessed 11 Apr 2018.

UNOPS (2008) Housing and property restitution for conflict-affected families: Pilot study in the Mannar DS Division, Mannar District. UNOPS Applied Research Unit. United Nations Office for Project Services, Colombo.

UNOPS (2010) Needs assessment of Vanni IDPs returning to Jaffna district, Velanai Divisional Secretariat Division: based on qualitative data. UNOPS Applied Research Unit. United Nations Office for Project Services, Colombo.

Zetter R, Deikun C (2011) A new strategy for meeting humanitarian challenges in urban areas. Forced Migr Rev 38:48-50.

\section{Submit your manuscript to a SpringerOpen ${ }^{\circ}$ journal and benefit from:}

- Convenient online submission

- Rigorous peer review

- Open access: articles freely available online

High visibility within the field

- Retaining the copyright to your article

Submit your next manuscript at $\boldsymbol{\nabla}$ springeropen.com 